\title{
Quantitative Aspects about the Interactions of Professors in the Learning Management System during a Final Undergraduate Project Distance Discipline
}

\author{
Cristian Cechinel \\ Faculty of Education (FaE), \\ Federal University of Pelotas, Pelotas, RS, Brazil \\ contato@cristiancechinel.pro.br
}

\begin{abstract}
This work presents a quantitative study of the use of a Learning Management System (LMS) by the professors of a distance learning course, focused on the guidance given for the students' Final Undergraduate Project. Data taken from the logs of 34 professors in two distinct virtual rooms were collected. After pre-processing the data, a series of statistical methods were performed in order to observe the different aspects related to the access of these professors on the LMS during the course. It was possible to observe that the average number of interactions per student per professor is directly associated to the number of students advised by the professors. Moreover, it was also possible to observe that the two forms of interaction available in the virtual classroom (synchronous and asynchronous) did not present significant differences in relation to the average number of interactions per student per professor.
\end{abstract}

Keywords: Distance Education, Final Undergraduate Project, Moodle, Teaching Analytics, Interactions, Synchronous and Asynchronous Communication.

\section{Introduction}

Online Distance Education (ODE) in Brazil had its expansion fostered by the introduction of the Open University of Brazil (UAB) (SEED/MEC, n.d.) in 2006. During these 8 years of the program, ODE has been consolidating itself as one feasible alternative for the expansion of undergraduate education in several regions of the country, with approximately 268,028 students (in 171,084 different undergraduate courses) spread throughout more than 636 cities.

In Brazil, students from ODE have been achieving good results in the National Exam of Students Performance (ENADE), sometimes better results than the students coming from traditional courses (AcheSeuCurso, 2013; Silva, Oliveira, \& Mourão, 2012). Studies from other authors also

Material published as part of this publication, either on-line or in print, is copyrighted by the Informing Science Institute. Permission to make digital or paper copy of part or all of these works for personal or classroom use is granted without fee provided that the copies are not made or distributed for profit or commercial advantage AND that copies 1) bear this notice in full and 2) give the full citation on the first page. It is permissible to abstract these works so long as credit is given. To copy in all other cases or to republish or to post on a server or to redistribute to lists requires specific permission and payment of a fee. Contact Publisher@InformingScience.org to request redistribution permission. corroborate that ODE tends to be as effective or more effective than traditional methods of course delivery (Swan, 2003). ODE is being adopted by the Brazil Federal Government as a strategy for the democratization and interiorization of higher education in the country. There is even an initial proposal from the Ministry of Education (MEC) for the creation of a Federal Open University of Brazil (Foreque, 2013) that would bring 
together the existing UAB initiatives in a single University, as already happens in other countries such as: Spain (Universidad Nacional de Educación a Distancia - www.uned.es), United Kingdom (The Open University - www.open.ac.uk) and Netherlands (Open Universiteit Nederland www.ou.nl).

The different universities that participate in UAB have been adopting distinct strategies in the execution of their pedagogical and administrative policies. In this myriad of organizational possibilities in a field still in formation, each institution needs to establish their own parameters of quality in this format, and to develop an understanding of all the aspects involving the execution of their activities. The funding provided by the Brazilian government (the UAB program is managed by CAPES - Brazilian Federal Agency for the Support and Evaluation of Graduate Education) to implement and manage the distance courses through UAB, is budgeted based on the number of students and the different academic activities that must be executed throughout the courses, such as development of digital materials, supervision and administration of students internships, academic support, supervision of students' final projects and management of virtual rooms. Even though universities are aware of the government parameters (e.g., number of grants/financial aid per student), such parameters still need to be pedagogically validated in order to develop a solid ground for ODE in Brazil. A clear example of this situation is the financial aid granted by UAB for the implementation of the Final Undergraduate Project (FUP) discipline in distance courses. In order to implement FUP discipline in distance courses, UAB pays to each professor a two month grant for the guidance of 5 (five) students. Considering that one month grant requires a total working time of 80 hours ( 20 hours per week), each professor needs to dedicate a total of 32 work-hours per student to the FUP guidance process ( 80 hours per month times 2 months divided by 5 students equals to 32 hours per student). The number of hours per week per student will vary, depending on how each course structures its disciplines, but for a discipline that is implemented in 16 weeks (a regular semester of four months), each professor should dedicate at least 2 work-hours per week per student during the entire semester (here the work-hour is not exclusively related to the communication between the professor and his student, but to all the work related to the guidance process, such as the manuscript readings). Although the calculations to use such parameters are straightforward, there is no empirical evidence to support the parameters themselves, and much work still needs to be done in order to check whether these numbers correspond to the real needs of the disciplines or not.

The huge amount of data now available from the use of Learning Management Systems (LMS) in ODE courses, allows us to conduct initial studies that could help in the establishment of empirical parameters, based on real experiences of distance teaching and learning. The present work aims to initiate the development of these parameters, taking as a starting point quantitative data obtained from the use of a LMS, during the Final Undergraduate Project (FUP) discipline of a distance bachelor's course on Country Education (CE). In particular, the work focuses on analyzing different aspects of interaction between professors and their students during the writing of their Project. The FUP discipline of the CE distance course is placed in the last semester, with a total of 136 hours distributed in 10 weeks. Although it is possible to find in the literature other studies of the execution of FUP disciplines in the distance modality, the majority of those studies present either qualitative approaches, based on opinion surveys applied to professors and students, or quantitative approaches mainly focused on the students' success and failure rates, such as in Benfatti, Gomes, Costa, Brasil, and Ávila (2013) and Primo and Silva (2007). This work presents a more quantitative perspective, focused on the interaction between professors and students inside the LMS (Moodle) and placed in the field known nowadays as Academic Analytics. For the context of the present study, an interaction means a log record stored in the Moodle database as a consequence of the use of a virtual classroom of the discipline by the professor. 
The main goal here is to evaluate such interactions inside the LMS and to unveil relations that can help in planning future editions of the discipline considering its specificities. The rest of the work is structured as follows. The next section briefly presents the theoretical background and the research questions of the paper. The third section presents the organization of the discipline inside the LMS (Moodle), and the fourth section describes the methodology followed in the study. The fifth secion analyses and discusses the most important findings, and the sixth section presents some initial conclusions and possible future work.

\section{Background, Related Work, and Research Questions}

The notion of interaction with LMS is mentioned in several works related to ODE. Learning effectiveness/efficiency has often been associated to different measures of students' interactions inside LMS, that are normally highly correlated to their success in the courses. For instance, Murray, Pérez, Geist, and Hedrick (2013) observed that students who had the highest rates of access to the contents of a distance course inside a LMS, also receiving the highest grades, and Dickson (2005) found that the total number of clicks made by students is strongly correlated with the student's final grade in a course. Garrison, Anderson, and Archer (1999) have designed a conceptual framework identifying the critical elements that are required for a successful computer mediated educational experience. According to the authors, these core elements are cognitive presence (the extent to which one is able to construct meaning), social presence (the ability the student has to project himself to the others participants of the virtual community as a real person), and teaching presence (design of an educational experience and facilitating and enhancing cognitive and social presence for the achievement of learning outcomes). According to Swan (2003), each one of these elements can be equated to a different mode of interactivity that can directly affect learning efficiency: interactions with course (cognitive presence), interaction among peers (social presence), and student interactions with teachers/instructors (teaching presence).

Aware that interactions are key to map, predict, interpret, and understand learning efficiency in ODE, the present work focuses specifically on one of these different modes of interactions described in the literature: interaction with teachers/instructors. However, our goal here is slightly different from the existing studies that analyze interactions from the perspective of the student. Our perspective here is on the teachers' interactions in the very specific context of supervising the writing of the students' Final Undergraduate Projects (FUP). In this context the Final Undergraduate Project is a very particular discipline (module) within courses, as these projects normally demand some sort of independence of the student and a need for an "organized approach", for both student and teacher, for instance to cope with time management (Kelly, 1990). Differently from other disciplines, in FUP the teacher/advisor normally has a deeper and more personalized interaction with his students. This has to do with the fact that in such a discipline, teachers work with smaller groups of students (in comparison with a regular classroom), and that each student will have to write an individual article about a particular topic, which requires a unique approach, method, and bibliography.

The specifics of the FUP discipline is also reflected at UAB, as this governmental project uses a specific financial aid formula to compute how much money a given course will get to realize the discipline. UAB considers that advisors would expend approximately 32 work-hours to supervise a student during the writing of his final undergraduate project. Considering this, the present work aims to better understand how advisors interact with their students during the FUP discipline, implemented as a distance course, by analyzing their access logs in the LMS. The first research question we propose here is:

- $\quad$ RQ1 - Within the context of the present study, is the number of students per advisor associated to the average number of interactions per student per advisor? 
It is already established in the literature of Learning Analytics, that students' success in distance courses is directly correlated to their engagement inside Learning Management Systems (AgudoPeregrina, Iglesias-Pradas, Conde-González, \& Hernández-García, 2014; Jayaprakash, Moody, Lauría, Regan, \& Baron, 2014; Lykourentzou, Giannoukos, Nikolopoulos, Mpardis, \& Loumos, 2009; Smith, Lange, \& Huston, 2012; Valsamidis, Kontogiannis, Kazanidis, \& Karakos, 2011).The technology of distance learning allows tutors to measure engagement of students (Beer, Clark, \& Jones, 2010), by looking into system logs and evaluating the intensity of students' interactions in the different activities available inside virtual classrooms. The basic idea here is that the more the student interacts within the LMS, the greater are his chances of success in the discipline. The FUP discipline is different in the sense that the main students' interactions are with their advisor. Interactions between professors and students are very important in any kind of discipline (Anderson, Liam, Garrison, \& Archer, 2001), however in many disciplines, other kinds of interactions also take place, which contribute to learning and students' success (for instance, interactions with peers, with resources, and with tutors). In the FUP discipline there is a basic interaction between the student and his advisors, and as Swan (2003) says, "the quantity and quality of instructor interactions with students is linked to student learning".

The FUP discipline is treated by UAB differently from other disciplines and the budget allocated to realize it clearly depends on the number of students a given professor will supervise. UAB establishes that each professor will be paid a two month grant for the guidance of 5 (five) students. This is a reference budget that should be used by each institution according to its local reality, depending on the number of students to be guided, and the number of professors available for such tasks. If one is able to establish a negative association between the number of students supervised and the average number of interactions per student per advisor, this could help the administrators of the FUP discipline to better plan the discipline operation. For instance, during the planning stage of the discipline and the hiring of professors, instead of paying a four month grant for a given professor to guide say 10 students, it would be better to pay a smaller monthly grant for the guidance of a smaller group of students for the sake of not compromising the interactions between students and advisors during the discipline.

As we are considering here only interactions in the form of access logs, it is not possible at this stage to directly contrast our data with the parameters used by UAB to distribute financial aid (UAB considers work-hours that are different from log records). However, this work will serve to initiate the future construction of parameters based on real pedagogical experiences. If further studies are able to estimate the actual time spent inside the LMS during the guidance process, this could help $\mathrm{UAB}$ to calibrate its budget policy for the discipline based on practical experience. As the interaction with professors is considered critical for the success of students, it is important to understand whether the number of students supervised by professors affects their performance, in terms of interactions dedicated to each student, and what could be a desirable number of students for each professor.

The second goal of this paper is to evaluate how professors worked with the online tools provided by the administration of the discipline to foster communication with the students. As will be described in the next section, two different forms of communication between students and their advisors were provided: Forums (asynchronous) and Chats (synchronous). Synchronous and asynchronous means of communication are used within distance learning systems. Different studies have been conducted to evaluate the impact and usefulness of each of these in distance learning systems, and have led to different conclusions about the importance and efficacy of each modality of communication in e-learning. Hrastinski (2008) compared the benefits and drawbacks of asynchronous and synchronous e-Learning, describing asynchronous e-learning as a key component of flexible learning, as it allows communication at any time, and in combination with other activities of individuals (e.g., work, family), while synchronous learning helps students and teach- 
ers to better socialize and avoid frustration by interacting using real time questions. Offir, Lev, and Bezalel (2008) stated that asynchronous teaching methods do not foster a dialogue between teacher and student, and therefore do not enable students to raise questions, and that students prefer learning through a synchronous system. However, highly skilled students are able to overcome low-level interactions in asynchronous learning, for example, Andresen (2009) stated that asynchronous discussion forums can achieve high levels of learning, but offer some limitations. Andresen (2009) particularly mentioned difficulties students face in expressing themselves in problem-based learning, where discussions used to solve problems tend to be more specific and concrete. Andresen (2009) also mentioned that asynchronous forums also fostered reflection, engagement, and willingness to discuss in a multicultural education context and that learners felt they were involved in a less meaningful form of communication. Bassett (2011) presented a case study where students participated in asynchronous online discussion about three journal articles, where students valued the learning experience and perceived asynchronous learning as an inclusive place for collaboration and discussion. In order to achieve success in asynchronous activities, students reported the need of previous preparation and planning (Bassett, 2011). Schultz (2003) described a small experiment with his students, where he concluded that synchronous online discussions are not as effective as face-to-face synchronous discussions and suggested that online synchronous discussions should be combined with other online techniques such as forums.

The second research question of the present work is:

- $\quad$ RQ2 - Is there a significant difference in the number of interactions between students and professors, using synchronous and asynchronous forms of communication;

This analysis will help to evaluate whether these two modalities of e-learning are being used by the professors in complementary ways in the specific context of the FUP distance discipline. As previously mentioned, both modalities have their strengths and limitations, and there is a need for better understanding of how they are used within real case e-learning scenarios. Differences in the average number of interactions between these two modalities could indicate that professors and students tend to prefer one specific means of communication rather than the other, or that one kind of e-learning better suits the guidance process of the FUP. Even though quantitative analysis cannot provide reasons behind the differences between the two types of interactions (or the equivalences between them), it will serve the purpose of initially establishing the usefulness of such tools within the discipline.

The third research question has to do with communication between professors and the administration of the discipline. As the discipline was set up in two different virtual classrooms (one for communication between professors and students, and another for communication between professors and the administration), we would like to evaluate whether the average number of interactions of professors per student is related in both virtual classrooms. Therefore, the third research question of the present work is:

- RQ3 - Is the amount of interaction of the professors with the students related to the amount of interaction of the professors with the administration of the discipline?

As the discipline is executed over a short period of time, the communication between professors and the administration of the discipline is key to addressing any problems that may arise during the guidance process. Answering these questions will help faculty to understand how the course can be better structured to improve future implementation of this discipline. The next section will briefly describe how virtual classrooms were set up to implement the FUP discipline for our distance course. 


\section{Moodle Classrooms in the Final Undergraduate Project Discipline}

Two different virtual classrooms were set up in Moodle in order to support the Final Undergraduate Project discipline, which were the Guidance Classroom (GC) and the Advisors Classroom (AC).

The Guidance Classroom (GC) was set up for the interaction between advisors and their students, and it was the virtual classroom where the guidance for the development of the students FUP took place. In this classroom, students' activities were structured over 10 weeks, with activities scheduled to be submitted every week, according to the chapters the students had to write about their individual work $\left(1^{\text {st }}\right.$ and $2^{\text {nd }}$ weeks - Introduction; $3^{\text {rd }}$ to $6^{\text {th }}$ week - Methodology and Development; $7^{\text {th }}$ and $8^{\text {th }}$ weeks - Conclusions; $9^{\text {th }}$ week - review board; $10^{\text {th }}$ week - final revised version of the FUP). Materials explaining pedagogical and administrative aspects of the discipline were made available here, such as submission deadlines, activities, evaluation criteria, reference/citation styles, and a general document containing the whole team of advisors and their respective students. The GC was edited to allow two distinct means of communication between advisors and students: synchronous (chats) and asynchronous (forums). Forums were organized per professor, where each specific forum of a given professor was sub-divided into topics with the identification of his students.

In these forums, each professor guided their respective students through successive submissions of their FUP chapters. Along with the forums, advisors and students could also communicate through chats according to a pre-defined agenda that should be agreed between the students and advisors (normally once a week).

A second virtual classroom was set up, to allow communication between the advisors and the administrator of the discipline, the so-called Advisors Classroom (AC). In the AC, advisors should submit weekly a brief report about the guidance process, and evaluation boards could submit the final grades of the students' FUP. In order to facilitate the guidance process, profiles about the students (built during the 4 years of the course) were also made available for the advisors in this virtual classroom. Communication between the advisors and the administration was mainly performed through Forums.

The role of an advisor during the FUP discipline was twofold. Firstly, professors had to guide their group of students during the writing of their final undergraduate project. Among the tasks related to the guidance process are fostering discussions with the students about their project ideas, monitoring the quality of the writing project, suggesting relevant literature in the context of the students work, answering occasional and recurrent questions of the students about the direction of their work. Secondly, professors were required to keep in touch with the administration of the discipline and report how each one of their students were developing in the discipline. Moreover, professors needed to attend training and meetings with the administration of the discipline and help to evaluate the projects of other students.

\section{Methodology}

The study was performed through the following steps: 1) Collection of the advisors access logs in both virtual classrooms; 2) Pre-processing of the data; and 3) Data analysis.

\section{Data Collection}

Data was collected from the access logs of the 34 advisors, in both the GC and AC virtual classrooms set up for the discipline. In total, 34 professors guided 196 students during a period of 10 weeks, generating $\log$ files with a total of 63,066 records in the GC, and 15,334 records in the 
AC. A record here means a row in the log file, representing a certain kind of interaction that the user (the advisor) performed in that virtual classroom in Moodle. In a single access to Moodle, a user can perform several distinct interactions (Moodle, 2013). Table 1 presents the format of the collected $\log$ files.

\begin{tabular}{|c|l|}
\hline \multicolumn{2}{|c|}{ Table 1: Information inside the log files } \\
\hline Columns & \multicolumn{1}{|c|}{ Comments } \\
\hline Course & \multicolumn{1}{|c|}{ Name of the virtual classroom accessed (GC or AC). } \\
\hline Time & \multicolumn{1}{c|}{ Data and time of the access. } \\
\hline $\begin{array}{c}\text { IP Ad- } \\
\text { dress }\end{array}$ & \multicolumn{1}{c|}{ Name of the advisor. } \\
\hline \begin{tabular}{c} 
Full Name \\
\hline Action
\end{tabular} & $\begin{array}{l}\text { The action represents the type of interaction that the advisor performed in the classroom. In this } \\
\text { study the actions were as follows: } \\
\text { 1) Observing the student submission, update of the student grade; } \\
\text { 2) Visualization and participation on chats; } \\
\text { 3) Visualization and inclusion of posts in forums; } \\
\text { 4) Visualization of resources; } \\
\text { 5) Visualization of the course; } \\
\text { 6) Visualization of the user. }\end{array}$ \\
\hline $\begin{array}{l}\text { Informa- } \\
\text { tion }\end{array}$ & \begin{tabular}{l} 
Specific activity, resource or student accessed in the given interaction. \\
\hline
\end{tabular} \\
\hline
\end{tabular}

Advisors can be divided in 4 distinct groups, considering the number of students they have guided, as follows: professors who guided 1 (one) student, 2 (two) students, 8 (eight) students and 10 (ten) students. These differences are due to the fact that some of the professors were hired through a selection process for a part-time job (20 hours week) exclusively for that activity and that defined the support of 8 or 10 students for a period of 10 weeks, while other professors were already hired for other activities inside the course and were not dedicating their time entirely for the guidance of students. This second group of "volunteers" guided a smaller number of students ( 1 or 2 ) and was also involved in other activities within the course. From the whole group of professors approximately 52\% (18) had no previous experience in ODE and were more concentrated in the groups who guided a higher number of students (all of the 18 professors with no previous ODE experience were guiding 8 or 10 students). It is important to highlight that the whole group of advisors also participated as members of the evaluation boards.

\section{Data Pre-processing}

A Python script was developed to group the different possible values for the column Action (Table 1) according to main categories of activity. In this way different actions belonging to the same kind of activity were grouped into one single category. For instance, actions of visualization, sending, and updating of a given assignment were grouped into the category named "Assignment". The five resulting categories were 1) Assignment, 2) Forum, 3) Chat, 4) Course, and 5) Resource. Table 2 presents some examples of the original values of the column Action and the resulting categories into which they were grouped. 
Table 2: Examples of original values in the action column

\begin{tabular}{|l|l|}
\hline Original value in the action column & Category \\
\hline assignment view (http://moodle.ufpel.edu.br/clec/mod/assignment/view.php?id=2287) & Assignment \\
\hline $\begin{array}{l}\text { assignment update grades } \\
\text { (http://moodle.ufpel.edu.br/clec/mod/assignment/submissions.php?id=2282\&amp,user=15 } \\
60)\end{array}$ & Assignment \\
\hline $\begin{array}{l}\text { forum view forum (http://moodle.ufpel.edu.br/clec/mod/forum/view.php?id=2327) } \\
\text { forum add post (http://moodle.ufpel. edu.br/ clec /mod/forum/ discuss. } \\
\text { php?d=1847\&amp,parent=50480) }\end{array}$ & Forum \\
\hline $\begin{array}{l}\text { chat talk (http://moodle.ufpel.edu.br/clec/ mod/chat/view.php?id=2380) } \\
\text { chat view (http://moodle.ufpel.edu.br/ clec/mod/chat/view.php?id=2380) }\end{array}$ & Chat \\
\hline course view (http://moodle.ufpel.edu.br/ clec/course/view.php?id=42) & Chat \\
\hline resource view (http://moodle.ufpel.edu.br/ clec/mod/resource/view.php?id=2215) & Course \\
\hline
\end{tabular}

\section{Analysis and Discussion}

The average number of interactions per advisor per student (ANIAS) was calculated by the sum of all interactions of a given advisor in a given virtual classroom divided by the number of students guided by him. The ANIAS presented huge differences in each of the virtual classrooms and did not present a normal distribution in either of them. As it can be seen in Table 3, on average, each advisor performed approximately 453 interactions per student in the GC (45.3 interactions per student per week) and 128 interactions per student in the $\mathrm{AC} \mathrm{(12.8} \mathrm{interactions} \mathrm{per} \mathrm{stu-}$ dent per week).

\begin{tabular}{|l|l|l|}
\hline \multicolumn{3}{|c|}{$\begin{array}{c}\text { Table 3: Descriptive statistics of the average number of interactions per advisor } \\
\text { per student in both virtual classrooms }\end{array}$} \\
\hline Measure & GC & AC \\
\hline Mean (ANIAS) & 453.291 & 128.537 \\
\hline Standard Deviation & 371.853 & 117.752 \\
\hline Coefficient of Variation & $82.034 \%$ & $91.6093 \%$ \\
\hline Minimum & 93.5 & 23.0 \\
\hline Maximum & 1954.0 & 556.0 \\
\hline Range & 1860.5 & 533.0 \\
\hline
\end{tabular}

Moreover, the standard deviation is extremely high in both virtual classrooms (371 for GC and 117 for AC), showing a huge asymmetry on the number of interactions per advisor per student. Figure 1 illustrates this asymmetry.

Figure 1 presents the density function of the average number of interactions per advisor per student in both virtual classrooms. The density plot describes the probability for the variable on the $\mathrm{x}$ axis (i.e., average number of interactions) to take on a given value. As can be seen from Figure 1, there is a clear concentration in the left part of the graph, indicating that most of the advisors tend to interact less (between the minimum and the average number of interactions) and a few advisors tend to interact more (between the average and maximum number of interactions). For instance, for the case of the Guidance Classroom, most of the professors have between around 100 and 800 (from 0 to 0.8 ) and very few of them have more than 800 interactions (the tail of the blue curve). 
For the case of the Advisors Classroom (red curve), the concentration is more acute. Most of the professors presented from around 100 to 500 interactions, and a few of them presented more than 500 interactions.

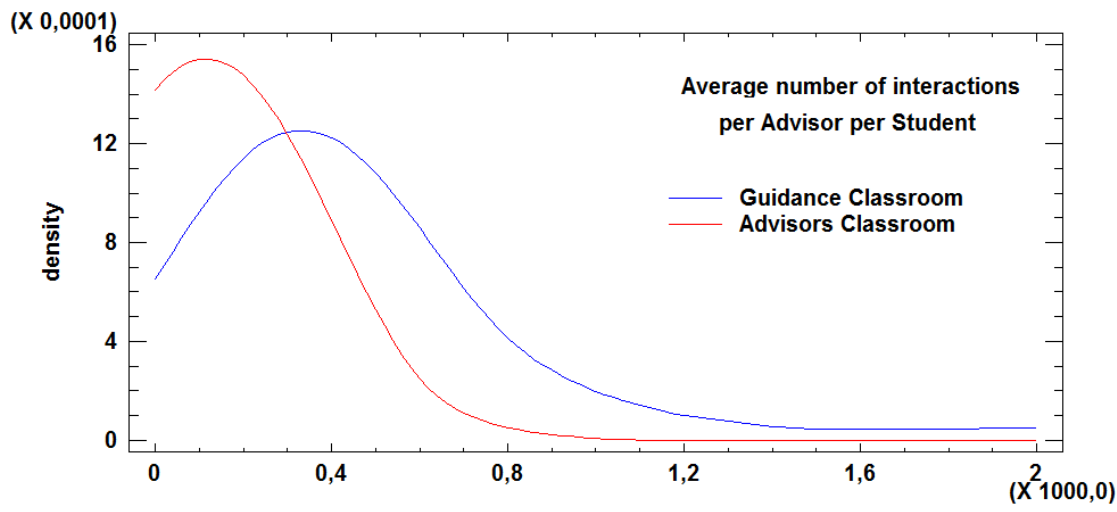

Figure 1: Density of interactions in both virtual classrooms

\section{Interactions per Category of Action}

Figures 2 and 3 present the ANIAS for each one of the categories of actions in each virtual classroom.

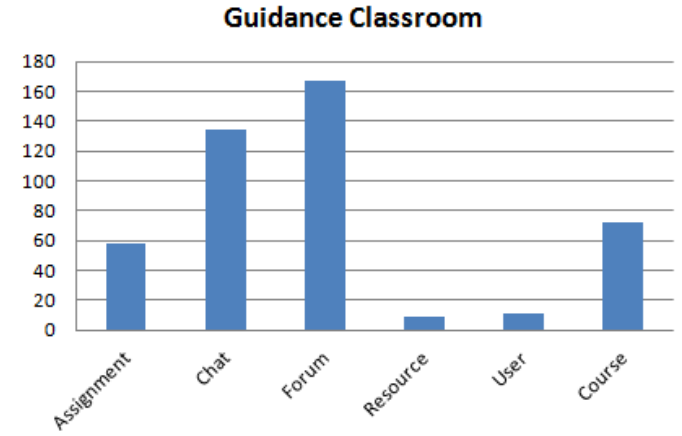

Figure 2: ANIAS for each category of action in the Guidance Classroom

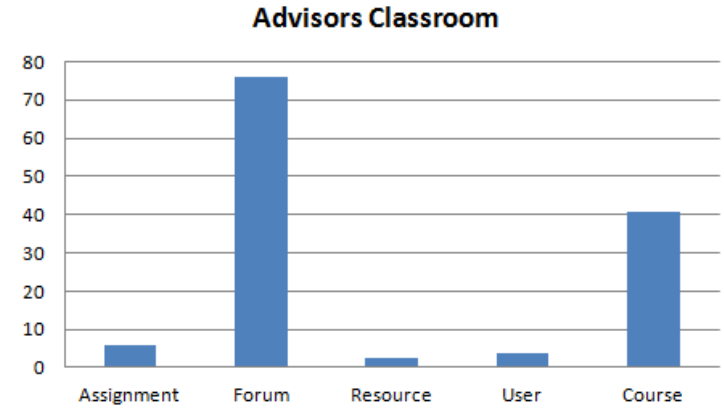

Figure 3: ANIAS for each category of action in the Advisors Classroom

As can be seen from Figure 2, the two most frequent actions are related to the guidance process itself (direct interaction between advisor and student), i.e., the use of forums for individualized guidance (approximately 167 per student, representing 37\% of the total) and the use of chats (134 per student, approximately $30 \%$ of the total). Moreover, $16 \%$ of the advisors interactions in the classroom were related to the visualization of the course and $13 \%$ to the control of the students assignments.

In the case of $\mathrm{AC}$ (Figure 3), the category of action with most interactions per advisor per student was the Forum (approximately 76 per student, representing $59 \%$ of the total), followed by the visualization of the course (approximately 40 per student, representing $32 \%$ of the total). It is important to highlight that this virtual classroom was set up exclusively to allow the communication between the professors and the administration of the discipline, as well as to make available the grades of the students. All these activities were performed through the use of Forums (Chat was not used in the $\mathrm{AC}$ virtual classroom). 


\section{Considerations Related to the Number of Students per Advisor}

As advisors guided different numbers of students during the discipline, we evaluated whether the number of students per advisor is associated to the ANIAS. Considering that the ANIAS did not follow a normal distribution, a Kruskal-Wallis test was performed to evaluate if there was significant difference between the medians of the ANIAS in the Guidance Classroom. The test presented significant difference at a 95\% level between the medians of the advisors that guided just 1 student and the medians of the other groups (professors who guided 2 students, 8 students and 10 students). Figure 4 shows these differences.

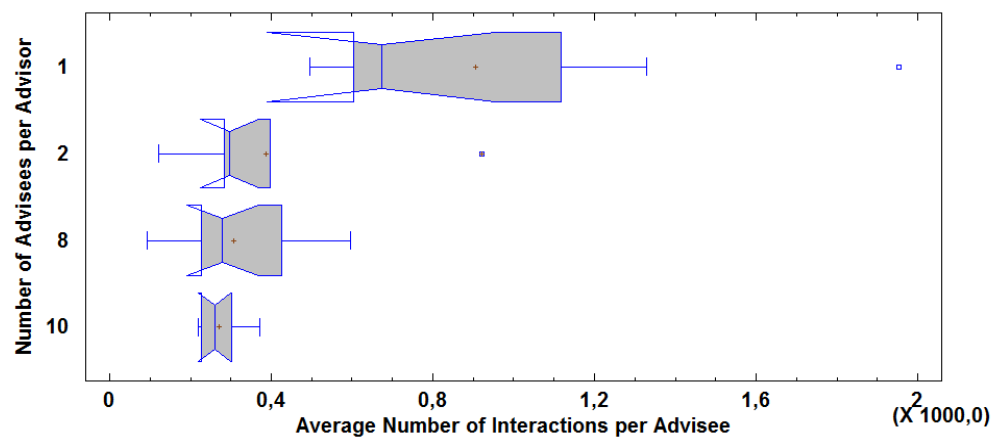

Figure 4: Notched box-plots of the average number of interactions per advisor per student (Guidance Classroom)

As can be seen from Figure 4, there is a clear tendency of an increase in the average number of interactions as the number of students guided by the professor decreases. This tendency is stronger in the group of advisors who guided just 1 student. This same test was also performed in the Advisors Classroom presenting similar results.

\section{Associations between the Average Number of Interactions in Both Virtual Classrooms}

As previously mentioned, activities available in both virtual classrooms had different purposes. We performed Spearman correlation test $\left(\mathrm{r}_{\mathrm{s}}\right)$ to evaluate whether there was any association between the average number of interactions in both virtual classrooms. We found a positive association with a coefficient $r_{s}=0.82$ at a $99 \%$ level of significance. The $r_{s}$ coefficient varies between -1 and 1 , where 0 means there is no association. The closer the coefficient gets to 1 , the better is the association. Figure 5 presents the scatterplot that illustrates the strength of this association.

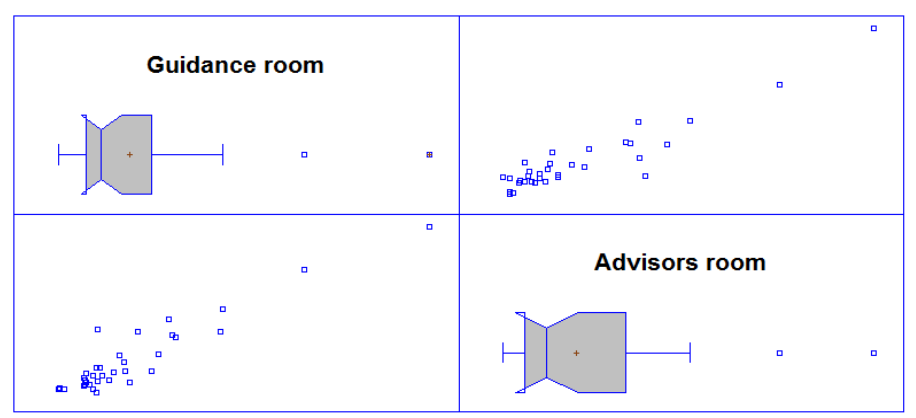

Figure 5. Scatterplot of the associations between the average number of interactions in both virtual classrooms 
In the context of the present study, this association indicates that the advisors exhibit the same kind of behavior (in terms of interactions per student) in both classrooms. A Linear Regression Analysis demonstrates that it is possible to predict with $87 \%$ probability $\left(\mathrm{R}^{2}\right)$ the average number of interactions of one virtual classroom compared to the average number of interactions of the other, at a $99 \%$ significant level.

\section{Chat versus Forums in the Guidance Room}

Finally an analysis was performed to evaluate the differences related to the interactions of advisors, considering the type of communication with their students, i.e., whether there were differences in the average number of interactions in Chats (synchronous) and Forums (asynchronous). A Mann-Whitney test was used to evaluate the differences between the medians of the number of interactions in these two activities, and a Kolmogorov-Smirnov test was applied to verify the differences between their distributions. Figures 6 and 7 present the visualization of this analysis.

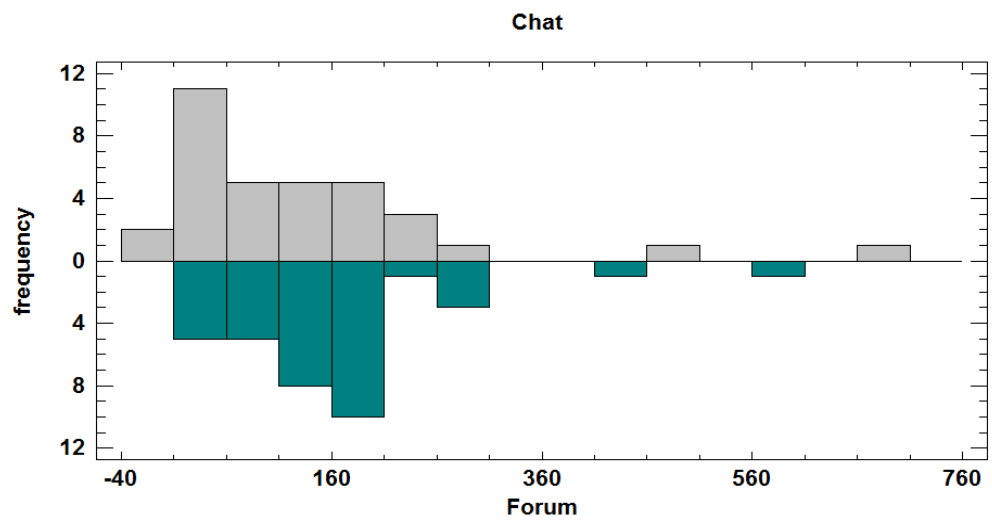

Figure 6: Histogram of the average number of interactions Chat versus Forum (Guidance classroom).

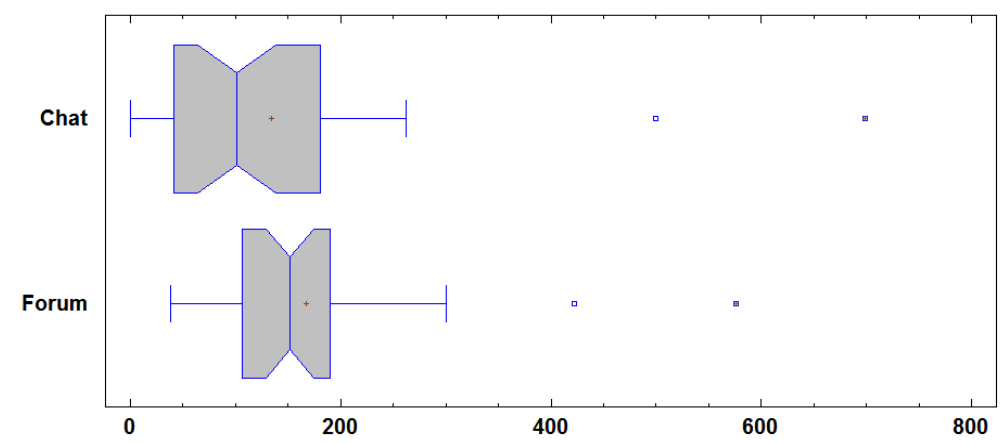

Figure 7: Notched box-plots of the average number of interactions - Chat versus Forum (Guidance classroom).

The tests indicated that there was no significant difference between the medians and the distributions of the two types of communication. This means that both ways of communication during the guidance process are equally used by tutors and relevant in the FUP discipline. 


\section{Conclusions and Future Work}

This paper has presented a quantitative analysis of the advisors interactions inside two virtual classrooms during the Final Undergraduate Project discipline. In order to conduct such a study, data about advisors' access logs was collected and pre-processed, using a Python script. Statistical analysis allowed us to observe three main aspects related to the way professors interact inside the virtual classrooms during the discipline, and to answer the research questions we established in Section 2.

- RQ1 - Within the context of the present study, is the number of students per advisor associated to the average number of interactions per student per advisor?

There is a negative association between the number of students that a given professor guides and the average number of interactions performed by that professor inside the LMS. According to the analysis, the higher the number of students an advisor supports, the lower the average number of interactions per advisor per student (ANIAS).

It is difficult to establish the reasons why the number of interactions is negatively associated to the number of students. One possibility could be the fact that professors with a higher number of students could feel under pressure (with less time to dedicate to guidance) and they consequently diminish their interactions with the students. Another reason to consider is that professors who guided 1 or 2 students were voluntarily acting as advisors, as well being already experienced in ODE and involved in other activities of the course. For instance, many of them already knew their students from previous disciplines. On the other hand, all the professors who supervised 8 or 10 students were experiencing ODE for the first time, did not have previous contact with their students, and this was the only distance activity they were involved with. It is possible, for instance, that professors who already knew their students tended to interact more with them, or that professors who were already experienced in ODE were more accustomed to navigation within the learning management system, and therefore interacted more with their students.

For the sake of future planning of the FUP discipline, future work will focus on studying these possible reasons as well as on trying to identify the ideal number of students that should be allocated for each advisor.

- RQ2 - Is there a significant difference in the number of interactions between students and professors, using synchronous and asynchronous forms of communication

There is no significant difference between the average number of interactions when comparing the interactions in Chats and Forums. This means that both means of communication between advisors and students are equally used and important in the Final Undergraduate Project discipline.

Future work will also consider the amount of hours each professor dedicated to the guidance process, and contrast this with the different types of possible actions inside the LMS. Moreover, qualitative analysis of the importance of both ways of communication will also take place by interviewing the opinions of professors and students regarding this matter.

- RQ3 - Is the amount of interaction of the professors with the students related to the amount of interaction of the professors with the administration of the discipline?

Patterns related to the average number of interactions per advisor per student (ANIAS) are positively associated in both virtual classrooms. This means that professors that had a higher average number of interactions in one virtual classroom did also present a higher average number of interactions in the other. Moreover, a Linear Regression Analysis showed that it is possible to predict, with $87 \%$ of probability, the interactivity of the professor in one virtual classroom, by knowing his interactivity in the other virtual classroom. It is important to highlight here that discovering 
correlations does not imply we are encountering cause and consequence relationships; correlation is a necessary condition for causality, and once it is observed it can be considered as "a good indication that some underlying causal relation exists" (Lagnado, Waldmann, Hagmayer, \& Sloman, 2006). Edward R. Tufte (2003) has resumed this idea using the following expression: "correlation is not causation but it sure is a hint". Finding the correlations is the first step needed to identify causation, but controlled studies are still needed to test true causal relationship.

One of the most important limitations of the present study is the small sample size that is being used in the analysis to answer the research questions. We intend to continue the present study by incorporating more data when new instances of the discipline are conducted. Future work will also include the number of hours dedicated by each professor in the LMS and will contrast these hours with the different interaction actions in the environment. In order to do that, another Python script will be written to calculate the time each professor stayed logged in to the LMS by using as a baseline, information about the IP address, the date and the access time. Such information will also allow us to compare the average time dedicated per advisor to each student with the current parameters under implementation by UAB. It is important to highlight that the guidance of Final Undergraduate Project is not restricted to the interactions inside the LMS. This work has a clear limitation in that it does not consider any other activity that may have occurred outside the virtual classrooms, such as the readings the professors need to do in order to guide the students. Future work will also consider such activities by collecting data directly from students and professors. Another limitation here is that we are evaluating only the interactions of the professors with the LMS and we are not evaluating students' interactions. Future work will also evaluate associations between the log accesses of the professors and the log accesses of the students. Other questions, such as the ones raised by Dzakiria, Idrus, and Atan (2005) could also be explored, i.e., whether the frequency of interactions is a meaningful measure of student success or failure, or if the pattern of interaction changes over the duration of the disciplines.

The findings of the present work will help us to plan the next instances of the FUP discipline, and can serve as a starting point to the creation of new ODE parameters that are based on real experiences of this form of support for students.

\section{Acknowledgements}

This work has been partially funded by CYTED (Ibero-American Programme for Science, Technology and Development) as part of project "RIURE - Ibero-American Network for the Usability of Learning Repositories“(code 513RT0471). Many thanks also go to the reviewers who have significantly contributed for the improvement of the final version of the paper with their insightful reviews.

\section{References}

AcheSeuCurso. (2013, 06/09/2013). Cursos a distância superam os presenciais em todos os indicadores de qualidade do e-MEC. Ache Seu Curso a Distância.

Agudo-Peregrina, Á. F., Iglesias-Pradas, S., Conde-González, M. Á., \& Hernández-García, Á. (2014). Can we predict success from log data in VLEs? Classification of interactions for learning analytics and their relation with performance in VLE-supported F2F and online learning. Computers in Human Behavior, 31, 542-550. doi: http://dx.doi.org/10.1016/j.chb.2013.05.031

Anderson, T., Liam, R., Garrison, D. R., \& Archer, W. (2001). Assessing teacher presence in a computer conferencing context. Journal of the Asynchronous Learning Network, 5(2), 17.

Andresen, M. A. (2009). Asynchronous discussion forums: Success factors, outcomes, assessments, and limitations. Journal of Educational Technology \& Society, 12(1). 
Bassett, P. (2011). How do students view asynchronous online discussions as a learning experience? Interdisciplinary Journal of E-Learning \& Learning Objects, 7, 69-79. Retrieved from http://www.ijello.org/Volume7/IJELLOv7p069-079Bassett744.pdf

Beer, C., Clark, K., \& Jones, D. (2010). Indicators of engagement. Paper presented at the Curriculum, technology \& transformation for an unknown future. Proceedings ascilite Sydney 2010.

Benfatti, E. d. F. S. S., Gomes, C., Costa, C. M. d., Brasil, L. L., \& Ávila, S. d. P. (2013). Orientação de TCC em Ambiente Virtual de Aprendizagem: Uma Pesquisa Ação. Paper presented at the X Congresso Brasileiro de Ensino Superior a Distância (ESUD 2013), Belém (Pará).

Dickson, W. P. (2005). Toward a deeper understanding of student performance in virtual high school courses: Using quantitative analyses and data visualization to inform decision making. Retrieved from https://www.msu.edu/user/pdickson/talks/DicksonNCREL2005.pdf

Dzakiria, H., Idrus, R. M., \& Atan, H. (2005). Interaction in open distance learning: Research issues in Malaysia. Malaysian Journal of Distance Education, 7(2), 57-69.

Foreque, F. (2013, 17/06/2013). MEC vai criar universidade federal de educação a distância, Folha de São Paulo. Retrieved from http://folha.com/no1296621

Garrison, D. R., Anderson, T., \& Archer, W. (1999). Critical inquiry in a text-based environment: Computer conferencing in higher education. The Internet and Higher Education, 2(2), 87-105.

Hrastinski, S. (2008). Asynchronous and synchronous e-learning. Educause Quarterly, 31(4), 51-55.

Jayaprakash, S. M., Moody, E. W., Lauría, E. J., Regan, J. R., \& Baron, J. D. (2014). Early alert of academically at-risk students: An open source analytics initiative. Journal of Learning Analytics, 1(1), 647.

Kelly, M. (1990). Supervising undergraduate projects. Educational Technology Centre.

Lagnado, D. A., Waldmann, M. R., Hagmayer, Y., \& Sloman, S. A. (2006). Beyond covariation: Cues to causal structure. In A. Gopnik \& L. Schulz (Eds.), Causal learning: Psychology, philosophy, and computation. Oxford University Press.

Lykourentzou, I., Giannoukos, I., Nikolopoulos, V., Mpardis, G., \& Loumos, V. (2009). Dropout prediction in e-learning courses through the combination of machine learning techniques. Computers \& Education, 53(3), 950-965. doi: http://dx.doi.org/10.1016/j.compedu.2009.05.010

Moodle. (2013). Logs. Retrieved December 11th, 2013, from http://docs.moodle.org/24/en/Logs

Murray, M., Pérez, J., Geist, D., \& Hedrick, A. (2013). Student Interaction with content in online and hybrid courses: Leading horses to the proverbial water. Informing Science: The International Journal of an Emerging Transdiscipline, 16, 99-115. Retrieved from http://www.inform.nu/Articles/Vol16/ISJv16p099-115MurrayFT114.pdf

Offir, B., Lev, Y., \& Bezalel, R. (2008). Surface and deep learning processes in distance education: Synchronous versus asynchronous systems. Computers \& Education, 51(3), 1172-1183. doi: http://dx.doi.org/10.1016/j.compedu.2007.10.009

Primo, L., \& Silva, C. R. d. O. e. (2007). A Prática de Orientação a Distância na Elaboração de TCCs.

Schultz, R. A. (2003). The effectiveness of online synchronous discussion. Proceedings of the Informing Science and Information Technology Joint Education Conference, Finland.

SEED/MEC. (n.d.).Presentation of EaD. Retrieved from http://portal.mec.gov.br/seed/arquivos/pdf/livreto_ingles.pdf

Silva, J. A. R. e., Oliveira, F. B. d., \& Mourão, L. (2012). Uma comparação entre cursos a distância e presencial. Paper presented at the $18^{\circ}$ CIAED Congresso Internacional ABED de EaD - "Histórias, Analíticas e Pensamento “Aberto" - Guias para o Futuro da EAD“, São Luís (Maranhão). 
Smith, V. C., Lange, A., \& Huston, D. R. (2012). Predictive modeling to forecast student outcomes and drive effective interventions in online community college courses. Journal of Asynchronous Learning Networks, 16(3), 51-61.

Swan, K. (2003). Learning effectiveness online: What the research tells us. Elements of Quality Online Education, Practice and Direction, 4, 13-47.

Tufte, E. R. (2003). The cognitive style of Power Point. Graphics Press.

Valsamidis, S., Kontogiannis, S., Kazanidis, I., \& Karakos, A. (2011). E-Learning platform usage analysis. Interdisciplinary Journal of E-Learning and Learning Objects, 7(1), 185-204. Retrieved from http://www.ijello.org/Volume7/IJELLOv7p185-204Valsamidis760.pdf

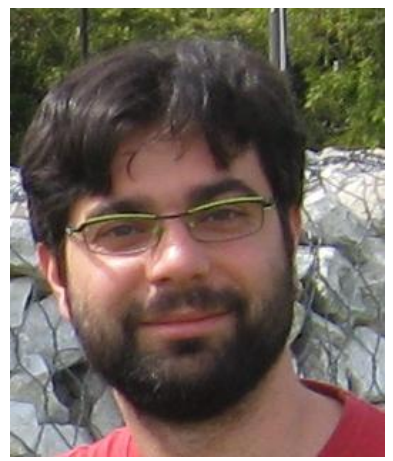

\section{Biography}

Dr. Cristian Cechinel (contato@cristiancechinel.pro.br) is a professor at the Faculty of Education (FaE) of the Federal University of Pelotas (UFPel/Brazil). He obtained his Bachelor's (1998) and Master's (2000) degree in Computer Science from Federal University of Santa Catarina (UFSC/Brazil), and his Ph.D. (2012) on Information and Knowledge Engineering at the Computer Science Department of University of Alcalá (UAH/Spain). He is an active member of the Latin-American Community on Learning Objects (LACLO). His research focuses on Learning Technologies, Metadata Quality, Learning Analytics, Artificial Intelligence and Distance Learning. 